(C) 2021, The Authors. Published by Elsevier Inc. and Fass Inc. on behalf of the American Dairy Science Association ${ }^{\circledR}$. This is an open access article under the CC BY-NC-ND license (http://creativecommons.org/licenses/by-nc-nd/4.0/).

\title{
Variations in $\mathbf{N}$-linked glycosylation of glycosylation-dependent cell adhesion molecule 1 (GlyCAM-1) whey protein: Intercow differences and dietary effects
}

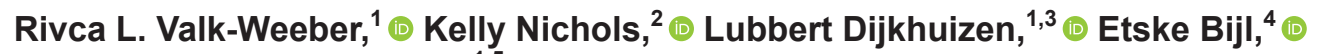 \\ and Sander S. van Leeuwen ${ }^{1,5 *}$ (1) \\ ${ }^{1}$ Microbial Physiology, Groningen Biomolecular Sciences and Biotechnology Institute (GBB), University of Groningen, Nijenborgh 7 , \\ 9747 AG Groningen, the Netherlands \\ ${ }^{2}$ Animal Nutrition Group, Wageningen University and Research, PO Box 338, $6700 \mathrm{AH}$ Wageningen, the Netherlands \\ ${ }^{3}$ CarbExplore Research BV, Zernikepark 12, 9747 AN Groningen, the Netherlands \\ ${ }^{4}$ Dairy Science and Technology, Food Quality and Design Group, Wageningen University and Research, PO Box 17, 6700 AA Wageningen, \\ the Netherlands \\ ${ }^{5}$ Sector Human Nutrition and Health, Laboratory Medicine, University Medical Center Groningen (UMCG), Hanzeplein 1, 9713 GZ, Groningen, \\ the Netherlands
}

\section{ABSTRACT}

In bovine milk serum, the whey proteins with the highest $\mathrm{N}$-glycan contribution are lactoferrin, $\mathrm{IgG}$, and glycosylation-dependent cellular adhesion molecule 1 (GlyCAM-1); GlyCAM-1 is the dominant $N$-linked glycoprotein in bovine whey protein products. Whey proteins are base ingredients in a range of food products, including infant formulas. Glycan monosaccharide composition and variation thereof may affect functionality, such as the interaction of glycans with the immune system via recognition receptors. It is therefore highly relevant to understand whether and how the glycosylation of whey proteins (and their functionality) can be modulated. We recently showed that the glycoprofile of GlyCAM-1 varies between cows and during early lactation, whereas the glycoprofile of lactoferrin was highly constant. In the current study, we evaluated intercow differences and the effects of macronutrient supply on the $N$-linked glycosylation profiles of the major whey proteins in milk samples of Holstein-Friesian cows. Overall, approximately $60 \%$ of the $\mathrm{N}$-glycan pool in milk protein was sialylated, or fucosylated, or both; GlyCAM-1 contributed approximately $78 \%$ of the total number of glycans in the overall whey protein $N$-linked glycan pool. The degree of fucosylation ranged from 44.8 to $73.3 \%$ between cows, and this variation was mainly attributed to the glycans of GlyCAM-1. Dietary supplementation with fat or protein did not influence the overall milk serum glycoprofile. Postruminal infusion of palm olein, glucose, and essential AA resulted in shifts in the degree of GlyCAM-1 fucosylation within individual cows, ranging in some cases from 50 to $71 \%$

Received July 15, 2020.

Accepted October 19, 2020.

*Corresponding author: s.s.van.leeuwen@umcg.nl difference in degree of fucosylation, regardless of treatment. Overall, these data demonstrate that the glycosylation, and particularly fucosylation, of GlyCAM-1 was variable, although these shifts appear to be related more to individual cow variation than to nutrient supply. To our knowledge, this is the first report of variation in glycosylation of a milk glycoprotein in mature, noncolostral milk. The functional implications of variable GlyCAM-1 fucosylation remain to be investigated. Key words: bovine whey glycoprotein, $N$-linked glycosylation, glycosylation-dependent cell adhesion molecule 1, dietary intervention, Holstein-Friesian

\section{INTRODUCTION}

Bovine milk serum contains $N$-glycosylated whey proteins. Glycan chains add diversity and functional characteristics to these proteins. For example, pathogenic bacteria recognize and adhere to specific glycan patterns that are present in the gut mucosa. The glycans present on ingested milk glycoproteins can act as decoys, preventing bacterial attachment (Barboza et al., 2012; Wang et al., 2017). $N$-Linked glycans can also interact with pattern-recognition receptors of the innate immune system, acting as immune-modulating agents (de Kivit et al., 2011; Figueroa-Lozano et al., 2018, 2020). Glycan modification with sialic acid or fucose residues is known to affect this receptor interaction (Varki and Gagneux, 2012; Falconer et al., 2018). The 3 main $N$-linked glycoproteins in bovine milk serum are IgG (0.1-0.5 mg/mL), lactoferrin (0.1-0.3 mg/ $\mathrm{mL}$ ), and glycosylation-dependent cellular adhesion molecule 1 (GlyCAM-1; also known as proteose peptone 3, PP3) or lactophorin $(0.3-1.2 \mathrm{mg} / \mathrm{mL}$; Conesa et al., 2005; Cheng et al., 2008; Valk-Weeber et al., 2020a). These proteins have distinct glycoprofiles by which they can be identified and quantified (Valk- 
Weeber et al., 2020a, b). Recently, it was identified that GlyCAM-1, a $37-\mathrm{kDa}$ glycoprotein with a single $\mathrm{N}$-glycosylation site that is always occupied, dominates the whey $N$-glycoprofile (Valk-Weeber et al., 2020a). The recognizable pattern of glycans expressed on any specific glycoprotein is generally constant and highly dependent on genetic regulation (Ohtsubo and Marth, 2006; Neelamegham and Mahal, 2016). However, glycan pattern can be altered under specific conditions, such as disease states (Rodrigues and Macauley, 2018), or under hormonal influences present at the onset of lactation (Takimori et al., 2011; Valk-Weeber et al., 2020c). In dairy cattle, the glycosylation pattern of lactoferrin isolated from milk collected at 3, 30, and 90 DIM was demonstrated to be highly stable within a single cow as well as between cows (Valk-Weeber et al., 2020c). The glycoprofile of GlyCAM-1 appeared to be less stable, as variations in the sialylated and fucosylated glycans of the same cow were observed in milk collected at 30 and 90 DIM (Valk-Weeber et al., 2020b).

The factors that affect GlyCAM-1 glycosylation remain unknown. We hypothesized that glycan synthesis could be modified by ingested nutrients. There is evidence for dietary influences on glycosylation, such as a decreased sialylation of liver proteins in rats as a result of a high-fat diet (Henriquez et al., 1979), and increased blood serum protein sialylation upon consumption of a polysaccharide supplement in humans (Alavi et al., 2011). Dietary effects on milk serum glycoproteins in ruminant species remain to be studied. Therefore, the main objective of this study was to investigate the relationship between nutrient supply and variation in the glycan concentration and glycoprofile of proteins in bovine milk serum. The second aim was to investigate the intra- and intercow variations in bovine whey protein glycosylation, with a specific focus on GlyCAM-1. We studied milk serum protein $\mathrm{N}$-glycosylation using previously described methods (Valk-Weeber et al., 2020a,b). By these methods, a detailed chromatogram of the $N$ linked structures of milk serum is generated, providing information on the structures present and their quantity. These detected structures can be further categorized to their protein of origin and provide a protein concentration estimate. These methods were applied toward milk samples from 2 studies that tested the effect of macronutrient supply on lactation performance of Holstein-Friesian dairy cattle (Nichols et al., 2018, 2019). Specifically, intercow variations in glycoprofile composition were studied in milk serum obtained from these experiments. We hypothesized that intracow variation could be induced by the dietary interventions used in these studies. We expected that the differences in diet composition and treatment administration between studies would allow elucidation of variation in glycan composition in response to nutrient composition and delivery in lactating ruminants.

\section{MATERIALS AND METHODS}

\section{Experiments and Milk Sample Collection}

All experimental procedures were conducted under the Dutch Law on Animal Experiments in accordance with EU Directive 2010/63 (European Commission, 2010).

Study A: Dietary Protein and Fat Supplementation. The complete study design has been described by Nichols et al. (2018). Briefly, 56 Holstein-Friesian cows (20 primiparous, $138 \pm 64$ DIM; 36 multiparous, $3.7 \pm 1.8$ lactations, $181 \pm 93$ DIM) were used in a randomized complete block design where supplemental energy from protein or fat was tested in a factorial arrangement. The study consisted of 2 successive periods (control and experimental), each consisting of $21 \mathrm{~d}$ of diet adaptation and $7 \mathrm{~d}$ of measurement. A basal TMR (consisting of $34 \%$ grass silage, $33 \%$ corn silage, $5 \%$ grass hay, and $28 \%$ concentrate on a DM basis; described in detail by Nichols et al., 2018) was fed during the control period. Cows were blocked based on similar parity, DIM, and DMI (4 cows per block) during the final $7 \mathrm{~d}$ of the control period. These animal characteristics were determined as those that would most affect the response to the dietary treatments, and were thus chosen as blocking criteria. Cows were randomly assigned (within block) to 1 of 4 dietary treatments during the experimental period: (1) low protein, low fat, (2) high protein, low fat, (3) low protein, high fat, and (4) high protein, high fat. The high-protein and highfat diets were obtained by restricting the basal diet intake of individual cows by $5 \%$ and supplementing 2.0 $\mathrm{kg}$ of a 50:50 mixture (DM basis) of rumen-protected soybean meal and rapeseed meal (high protein; SoyPass + RaPass; both xylose-treated; Borregaard LignoTech, Sarpsborg, Norway) or $0.68 \mathrm{~kg}$ of rumen-inert hydrogenated long-chain fatty acids (high fat; mainly C16:0 and C18:0; Hidropalm, Norel, Madrid, Spain) into the concentrate portion of the TMR.

Cows were milked twice daily at 530 and $1630 \mathrm{~h}$. Milk samples from individual cows were collected at 2 subsequent morning and afternoon milkings (fixed volume of milk per kilogram of milk produced) in the final $7 \mathrm{~d}$ of each period. Milk samples from the morning and afternoon milkings were pooled by cow into a single sample per period and stored at $-20^{\circ}$ until glycoprofile analysis.

Study B: Postruminal Infusion of Glucose, Palm Olein, and AA. Effects of isoenergetic levels of glucose $(\mathbf{G G})$ or palm olein $(\mathbf{L G})$ at low $(\mathbf{L M P})$ and 
high (HMP) MP levels were tested using postruminal infusion. The complete study design has been described by Nichols et al. (2019). Briefly, 6 rumen-fistulated Holstein-Friesian cows each received 6 experimental infusion treatments according to a randomly assigned 6 $\times 6$ Latin square design (all 6 cows were subjected to the 6 experimental infusions in varying orders). Within the Latin square, each treatment immediately preceded and followed each other treatment exactly once in each square and is therefore balanced for first-order carryover effects (Williams, 1949). The infusion periods consisted of $5 \mathrm{~d}$ of continuous abomasal infusion followed by $2 \mathrm{~d}$ of no infusion. The infusion treatments consisted of (1) saline (control; LMP-C), (2) GG (1,319 g/d; LMP-GG), (3) LG (676 g/d; LMP-LG), (4) EAA infused in a casein profile (844 g/d; HMP-C), (5) GG $(1,319 \mathrm{~g} / \mathrm{d})$ plus EAA (844 g/d; HMP-GG), and (6) LG $(676 \mathrm{~g} / \mathrm{d})$ plus EAA (844 g/d; HMP-LG). Infusion dosages (g/d) of LMP-GG, LMP-LG, and HMP-C were designed to be isoenergetic based on the gross energy content of the EAA infusion $(24.3 \mathrm{MJ} / \mathrm{kg})$ and an assumed $80 \%$ digestibility of LG (NRC, 2001) and $100 \%$ digestibility of EAA and GG. Cows were fed a TMR consisting of $42 \%$ corn silage, $31 \%$ grass silage, and $27 \%$ concentrate (DM basis; described in detail by Nichols et al., 2019).

Cows were milked twice daily at 530 and $1530 \mathrm{~h}$. Milk samples (5 g of sample/ $\mathrm{kg}$ of milk produced) from individual cows (morning and afternoon milkings) from the final $3 \mathrm{~d}$ of each infusion period were pooled into a single sample per cow and stored at $-20^{\circ} \mathrm{C}$ until glycoprofile analysis.

\section{Whey Protein Separation, Glycan Release, and Labeling}

Milk samples were processed according to the procedures described by Valk-Weeber et al. (2020a,b). Milk aliquots of $1 \mathrm{~mL}$ were thawed in a water bath $\left(37^{\circ} \mathrm{C}\right.$ for $30 \mathrm{~min}$ ), homogenized by regular inversion, and defatted by centrifugation $\left(4,000 \times g\right.$ for $10 \mathrm{~min}$ at $\left.4^{\circ} \mathrm{C}\right)$. Milk serum was prepared by acidifying defatted milk to $\mathrm{pH} 4.6$ using ammonium acetate buffer $(125 \mathrm{mM}$, $\mathrm{pH} 4.6)$ in a $1: 1(\mathrm{vol} / \mathrm{vol})$ ratio. Caseins were pelleted by centrifugation $\left(11,000 \times g\right.$ for 5 min at $\left.20^{\circ} \mathrm{C}\right)$, and $100 \mu \mathrm{L}$ of the supernatant (milk serum, acid whey) was taken for the subsequent step. Lactose was removed from milk serum by protein precipitation with $400 \mu \mathrm{L}$ of methanol containing ammonium acetate $(100 \mathrm{mM})$, followed by supernatant removal after centrifugation $\left(11,000 \times g\right.$ for $5 \mathrm{~min}$ at $\left.20^{\circ} \mathrm{C}\right)$. The resulting whey protein pellets were redissolved in $75 \mu \mathrm{L}$ of $80 \mathrm{mM}$ phosphate buffer at $\mathrm{pH} 7.5$ containing $2 \%$ SDS and $2 \%$ $\beta$-mercaptoethanol, by warming to $37^{\circ} \mathrm{C}$ for $10 \mathrm{~min}$, followed by rigorous vortex mixing. Proteins were denatured by heating to $85^{\circ} \mathrm{C}$ for $15 \mathrm{~min}$ and cooled to room temperature before adding $25 \mu \mathrm{L}$ of $10 \%$ Nonidet P-40 (NP-40 substitute, Sigma-Aldrich Chemie N.V., Zwijndrecht, the Netherlands). Glycans were released by peptide- $N$-glycosidase $\mathrm{F}$ treatment (100 units/ sample; PNGase F, Flavobacterium meningosepticum, New England Biolabs, Ipswich, UK). Glycan labeling via reductive amination and cleanup was performed as described by Ruhaak et al. (2008) and Valk-Weeber et al. (2020b), with anthranilic acid (Sigma-Aldrich) as the fluorescent label and 2-methylpyridine borane complex (Sigma-Aldrich) as the catalyst. Each glycan received a single fluorescent label at the reducing terminus. Analysis was performed in duplicate for study A; a single analysis was performed for study B.

\section{Chromatography and Chromatogram Analysis}

Fluorescently labeled glycans were separated by hydrophilic interaction liquid chromatography and measured by fluorescent detection (excitation wavelength: $330 \mathrm{~nm}$, emission wavelength: $420 \mathrm{~nm}$ ) according to the methods described by Valk-Weeber et al. (2020b). The HPLC chromatograms obtained from acid whey protein glycoprofile analysis were integrated using Chromeleon software (version 6.8, Thermo Fischer Scientific, Waltham, MA), with each chromatogram divided manually into 32 individual peaks on a fixed baseline (Figure 1). After integration, peak areas $(\mathrm{mV} \times \min )$ were generated for the 32 individual peak clusters. The glycan structures of all glycoproteins in the milk serum are represented in the obtained chromatograms. Previously, it was determined that the structures represented in the chromatogram originate primarily from GlyCAM-1, lactoferrin, and IgG (Valk-Weeber et al., 2020b). Each of these major glycoproteins expresses a unique glycan fingerprint. In previous work we structurally identified all glycans represented in the peak clusters of these glycoproteins (Valk-Weeber et al., 2020b). However, glycan structures of similar length and complexity coelute in 1 peak cluster, and some glycans may originate from more than 1 protein. Therefore, multiple structures can be present in a single peak cluster, with varying contributions to the total peak cluster area. In our current analysis, we simplified the chromatogram by allocating primary ( $\geq 50-90 \%)$, secondary (25-49), and minor $(\geq 25 \%)$ area-contributing structures (ValkWeeber et al., 2020b; Supplemental Table S1, http:/ /dx.doi.org/10.17632/88h99xfmp8.1). A single representative structure (i.e., the primary structure of each peak cluster) was taken into consideration, based on its dominant contribution to the total chromatogram peak area (Supplemental Table S1). For each of the 32 
Table 1. Overview of glycan peak clusters attributed to the major glycoproteins glycosylation-dependent cell adhesion molecule 1 (GlyCAM-1), lactoferrin, and IgG in bovine acid whey

\begin{tabular}{ll}
\hline Item & Peak cluster $^{1}$ \\
\hline Glycoprotein & $4,7-10,13-20,22-32$ \\
GlyCAM-1 & $1-3,5,6,11,12,21$ \\
Lactoferrin and IgG & $13-20,22-32$ \\
Glycan decoration & $8,10,11,14,16-20,23,25-27,31$ \\
Sialylated & Fucosylated
\end{tabular}

${ }^{1}$ Peak cluster numbers correspond to those referenced in Figure 1. For glycoprotein, peak clusters in chromatograms are shown that are associated with specific glycoproteins as described by Valk-Weeber et al. (2020b). For glycan decoration, peak clusters are shown that contain glycans with added sialic acid or fucose.

peak clusters, a single protein of origin (GlyCAM-1, IgG, lactoferrin) of the primary glycan structure was allocated (Table 1).

\section{Statistical Analysis}

Study A. Peak areas for the 32 individual peak clusters (Figure 1) obtained from the duplicate analyses were averaged. The proportions of GlyCAM-1 protein, sialylation, and fucosylation were calculated using the sum of the representative peak areas (Table 1) divided by the sum of the peak area of clusters 1 to 32. Groups were created for the evaluation of the effect of parity,
DIM, milk yield (MY), and DMI (Table 2) based on the characteristics of individual cows during the final $7 \mathrm{~d}$ of the control period. Variance in the proportion of GlyCAM-1, sialylation, and fucosylation as a result of parity, DIM, MY, and DMI (control period only) was analyzed by ANOVA using the GLM procedure of SAS (version 9.4; SAS Institute Inc., Cary, NC). Parity, DIM, DIM normalized by MY (DIMnorm), MY, and DMI were set as independent variables. The variable DIMnorm was calculated as the product of the DIM peak areas and MY $(\mathrm{kg} / \mathrm{d})$ divided by the mean MY $(\mathrm{kg} / \mathrm{d})$ in the control period. Multiple comparisons of least squares means between the lowest and highest group classification of each parameter were performed using a Tukey-Kramer adjustment. Differences were considered significant at $P<0.05$.

Variance in glycoprofile, as assessed by the total of the 32 individual integrated peak clusters (peak area) and the proportion of GlyCAM-1, sialylation, and fucosylation, was analyzed using the MIXED procedure of SAS (version 9.4). The level of protein and fat and their interaction were set as fixed effects, block was set as a random effect, and the parameters measured during the control period were used as covariates. Differences were considered significant at $P<0.05$.

Study B. The proportions of GlyCAM-1 protein, sialylation, and fucosylation were calculated using the sum of the representative peak areas (Table 1) divided

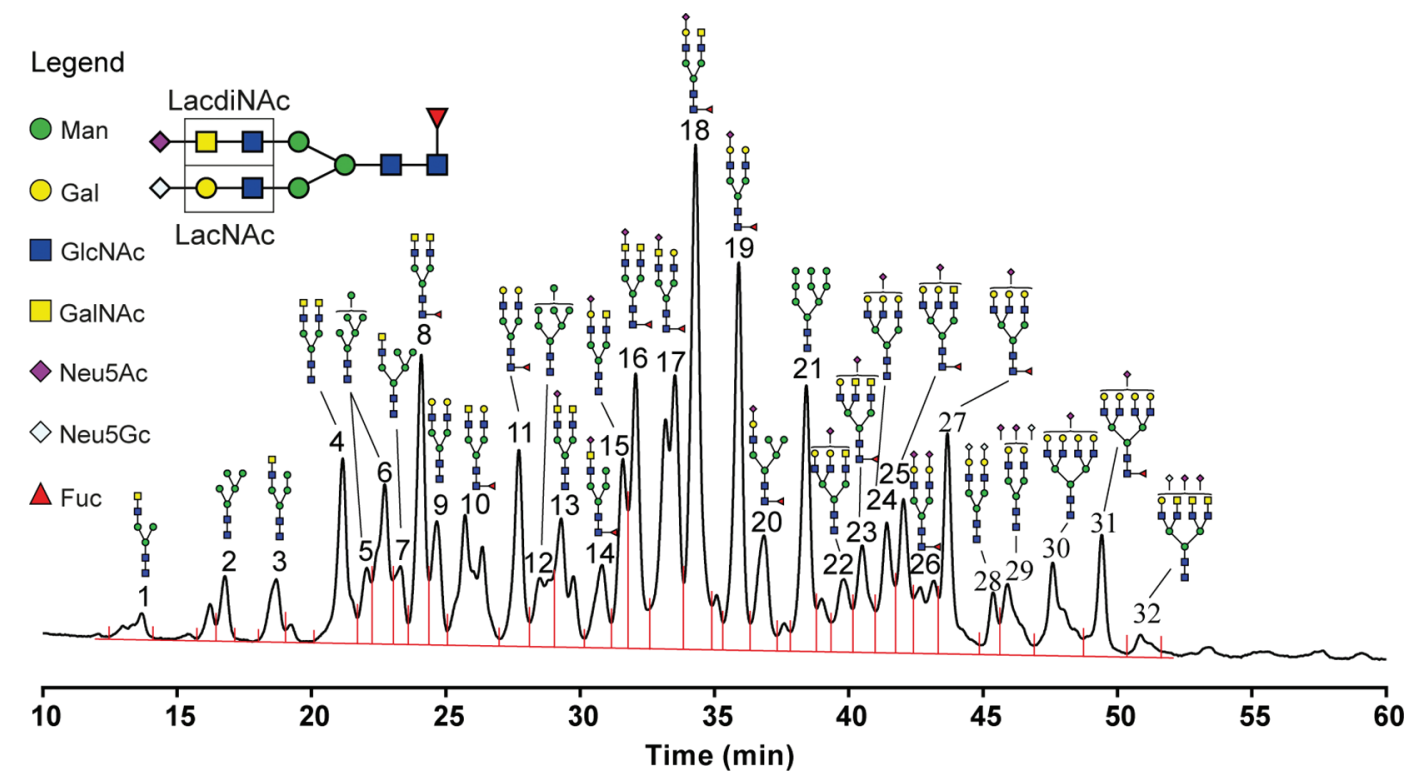

Figure 1. Chromatographic separation of glycans isolated from acid whey proteins showing the major contributing glycan structure for each of the 32 integrated peak clusters. A complete annotation of the glycan structures detected in a typical bovine whey glycoprofile is described by Valk-Weeber et al. (2020b). The symbols used to represent the building blocks and glycosidic linkages of a typical glycan structure are described in the legend. $\mathrm{Gal}=$ galactose; $\mathrm{Man}=$ mannose; Fuc $=$ fucose; GalNAc $=N$-acetylgalactosamine; GlcNAc $=N$-acetylglucosamine; Neu5Ac $=N$-acetylneuraminic acid; Neu5Gc $=N$-glycolylneuraminic acid. Common motifs: LacdiNAc $=$ GalNAc $\beta(1,4)$ GlcNAc; LacNAc $=$ Gal $\beta(1,4)$ GlcNAc. 
Table 2. Grouping of Holstein-Friesian cows in study A based on individual characteristics in the final $7 \mathrm{~d}$ of the control period (no. of cows in each group in parentheses)

\begin{tabular}{|c|c|c|c|c|c|c|c|}
\hline \multicolumn{2}{|c|}{ Parity (P) } & \multicolumn{2}{|c|}{ DIM } & \multicolumn{2}{|c|}{ Milk yield (MY) } & \multicolumn{2}{|r|}{ DMI } \\
\hline Group & Parity & Group & d & Group & $\mathrm{kg} / \mathrm{d}$ & Group & $\mathrm{kg} / \mathrm{d}$ \\
\hline P-2 & $2-3(17)$ & DIM-2 & $91-219(31)$ & MY-2 & $25-29.9(30)$ & DMI-2 & $19-21.9(22)$ \\
\hline P-3 & $\geq 4(19)$ & DIM-3 & $\geq 220$ & MY-3 & $\geq 34(13)$ & DMI-3 & $\geq 22(18)$ \\
\hline Average $^{1}$ & $2.8 \pm 1.9$ & Average & $166 \pm 87$ & Average & $29.6 \pm 5.5$ & Average & $20.6 \pm 2.2$ \\
\hline
\end{tabular}

${ }^{1}$ The average $\pm \mathrm{SD}$ value for each parameter $(\mathrm{n}=56 \mathrm{cows})$.

by the sum of the peak area of clusters 1 to 32 . Variance in glycoprofile, as assessed by the total of 32 integrated peak clusters and the proportion of GlyCAM-1, sialylation, and fucosylation, was analyzed using the MIXED procedure of SAS (version 9.4). The levels of $\mathrm{GG}, \mathrm{LG}$, and $\mathrm{AA}$ and their interaction $(\mathrm{GG} \times \mathrm{AA}$ and LG $\times$ AA), as well as period, were set as fixed effects and cow was a random effect. Differences were considered significant at $P<0.05$. We observed no carryover effects between periods, assessed by testing for an effect of the previous treatment in the ANOVA.

For the evaluation of intercow variation, cow, period, and treatment (LMP-C, LMP-GG, LMP-LG, HMP-C, HMP-GG, and HMP-LG) were set as fixed effects, with no random component. Multiple comparisons of least squares means by cow were performed with a TukeyKramer adjustment, and differences were considered significant at $P<0.05$.

\section{RESULTS AND DISCUSSION}

\section{Overall Whey Protein Glycoprofile Evaluation}

To evaluate the variation in whey protein glycoprofile, we used chromatograms to calculate the total peak cluster areas $(\mathrm{mV} \times \mathrm{min})$ and the contribution made by GlyCAM-1 glycans, as well as the ratio of fucosylated or sialylated structures or both, originating from GlyCAM-1, IgG, and lactoferrin (Table 3). It should be noted that glycan structures can be sialylated, fucosylated, both, or neither. Previously, we established that the observed peak cluster areas in the glycoprofile chromatograms have a direct relationship with the protein concentration in milk serum (Valk-Weeber et al., 2020a). Because each $N$-glycan receives 1 fluorescent label, and it was previously observed that labeling was nonselective for different $N$-glycan structures, the peak areas are representative of quantities of specific glycans (Bigge et al., 1995). The high level of variation observed in the values for total $\mathrm{N}$-glycan peak areas from the same amount of milk $(1 \mathrm{~mL})$, which ranged from 1,004 to $3,178 \mathrm{mV} \times \min$ across studies, indicated that the concentration of $\mathrm{N}$-glycosylated proteins varied greatly between cows in both studies. Because GlyCAM-1 has only $1 \mathrm{~N}$-glycosylation site, which is always occupied, there is a direct relationship between glycan peak cluster areas and protein concentration (Valk-Weeber et al., 2020a), and the GlyCAM-1 concentration in relationship to LF and IgG can be observed by their associated peak area ratio. The proportion of GlyCAM-1 glycans relative to the total chromatogram showed little variation regardless of study (overall average: $78.4 \pm 3.0 \%$ ), which indicated that the relative concentration ratio of GlyCAM-1:(lactoferrin + IgG) was maintained despite the fluctuations observed in the total peak area of the chromatogram (peak clusters 1-32). The contributions of sialylated $(59.7 \pm 3.7 \%)$ and fucosylated $(58.4 \pm$ $7.3 \%$ ) glycans were similar. The higher standard deviation for the fucosylated glycans suggests that these glycans varied relatively more than sialylated glycans. We hypothesized that variations in glycoprofile could originate from various factors such as intercow differences, cow characteristics such as parity, DIM, MY, and DMI, or nutrient supply to the animal.

\section{Effects of Parity, DIM, MY, and DMI}

The effects of parity, DIM, MY, and DMI were evaluated using the control period of study $\mathrm{A}$, as this study used a larger and relatively more heterogeneous group of cows compared with study B. The data are presented in Table 4, showing for each parameter the glycosylation data for the highest and lowest value group. The total $N$-glycosylated protein concentration, as indicated by the chromatogram total peak area, differed significantly with MY and DIM (Table 4). After normalization for MY, no significant differences in total peak area and the individual peak clusters were detected for DIM (DIMnorm). Milk yield, which generally decreases with increasing ( $>90 \mathrm{~d}$ ) DIM, thus appears to have a large effect on the milk protein concentration, which is consistent with earlier reports on total milk protein (Gellrich et al., 2014), IgG (Eisenberg et al., 2015), and lactoferrin (Cheng et al., 2008). Before the current study, this relationship had not yet been characterized for GlyCAM-1. The proportion of glycans 
Table 3. Variation in peak cluster area and composition in the glycoprofile chromatograms of study A and study $\mathrm{B}^{1}$

\begin{tabular}{|c|c|c|c|c|c|c|c|}
\hline Item $^{2}$ & \multicolumn{3}{|c|}{ Study A } & \multicolumn{3}{|c|}{ Study B } & $\frac{\text { Overall }}{\text { Mean } \pm \mathrm{SD}}$ \\
\hline Total peak area $(\mathrm{mV} \times \min )$ & 1,157 & 3,178 & $1,650 \pm 324$ & 1,004 & 1,537 & $1,295 \pm 96$ & $1,564 \pm 324$ \\
\hline Sialylated (\%) & 52.9 & 68.3 & $60.5 \pm 3.6$ & 49.0 & 60.7 & $57.2 \pm 2.7$ & $59.7 \pm 3.7$ \\
\hline Fucosylated (\%) & 44.8 & 73.3 & $60.2 \pm 5.9$ & 39.0 & 71.4 & $53.8 \pm 8.3$ & $58.4 \pm 7.3$ \\
\hline
\end{tabular}

${ }^{1}$ Study A: $n=56$ cows, 112 observations; study B: $n=6,36$ observations. Min = lowest observed value; Max = highest observed value.

${ }^{2}$ Calculations were performed using the cumulative peak areas $(\mathrm{mV} \times \min )$ of peak clusters 1-32 integrated according to Figure 1 and attributed to glycosylation-dependent cell adhesion molecule 1 (GlyCAM-1), sialylated, and fucosylated structures according to Table 1.

originating from GlyCAM-1 was not affected by DIM, MY, and DMI $(P \geq 0.11$; Table 4), indicating that the relative GlyCAM-1:(lactoferrin + IgG) concentration ratio was maintained. Therefore, with the increase in total $\mathrm{N}$-glycan peak area in the chromatogram as result of a lower MY, the concentration of GlyCAM-1 was increased in similar proportion to the concentration of lactoferrin plus IgG.

The concentrations of many whey proteins, including lactoferrin and IgG, are lower in primiparous cows than in multiparous cows (Raimondo et al., 2019). In this study, we observed that the proportion of glycans from GlyCAM-1 increased in cows of parity $1(80.9 \%)$ compared with cows of parity 4 or older $(77.1 \%$; $P<$ 0.01). Our results thus indicate that milk obtained from primiparous cows contains a relatively higher concentration of GlyCAM-1 versus lactoferrin and IgG. However, it is also possible that decreases in the protein concentration of lactoferrin and IgG in milk from primiparous cows resulted in the apparently higher GlyCAM-1 concentration.

Fucosylation and sialylation of the proteins was not affected by parity, DIM, MY, and DMI $(P \geq 0.44$; Table 4); therefore, the intercow and diet effects were investigated without further consideration of these parameters. The study design accounted for glycoprofile differences induced by the whey protein concentration by blocking cows by parity and DIM before treatment assignment.

\section{Cow Variation and Treatment Effects}

Study A. To visualize glycan structures responsible for the variation observed in the degree of fucosylation (Table 3), the glycoprofile chromatograms of a selection of cows from study A with high ( $70 \%$; group A), medium ( $\sim 60 \%$; group B), or low ( $\sim 45 \%$; group C) degree of fucosylation in the control period (2 representative cows shown per group) were plotted together with their respective chromatograms during the treatment period (Figure 2). A selection of glycan structures that either contained or lacked fucose was annotated in the chromatograms. Of this selection, structures $4,13,15$, 24 , and 30 lack fucose, whereas $8,16,18,19,27$, and 31 represent fucosylated structures (Valk-Weeber et al., 2020b; Figures 1 and 2); GlyCAM-1 is the main protein of origin for these fucosylated and nonfucosylated glycans (Valk-Weeber et al., 2020b; Table 1). By comparison of the glycoprofile chromatograms, we observed that cows that have a similar degree of fucosylation (i.e., high, medium, or low) also yield a visually similar glycoprofile (i.e., similarity between cow A1 and A2, cow B1 and B2, and cow $\mathrm{C} 1$ and $\mathrm{C} 2$; Figure 2). In cows that have a high degree of fucosylation (group A; Figure 2), fucosylated structures $(8,16,18,19,27$, and 31) dominated the glycoprofile. In contrast, in cows with a low degree of fucosylation (group C; Figure 2), fucosylated structures decreased and nonfucosylated structures $(4,13,15,24$, and 30) were present in relatively higher quantities. The selected chromatograms showed no or only minimal changes in response to the treatment diets irrespective of the initial fucosylation levels. The difference in the proportion of fucosylated glycans was $\leq 4 \%$ between the control and treatment periods for 51 out of 56 cows (Supplemental Table S2, http:// dx.doi.org/10.17632/88h99xfmp8.1). The proportion of fucosylated glycans was also not affected by protein or fat $(P \geq 0.14$; Table 5$)$. Instead, intercow variation appears to play an important role in the observed degree of GlyCAM-1 fucosylation.

The proportion of GlyCAM-1 increased in response to fat $(77.9 \%$ on low-fat diets; $79.0 \%$ on high-fat diets; $P=0.01$; Table 5). Milk fat concentration increased in response to fat in this study (Nichols et al., 2018). Studies have observed GlyCAM-1 both in the milk fat globule membrane (MFGM) and in a free form $(0.3-1.2 \mathrm{mg} / \mathrm{mL})$ in the serum fraction of milk $(\mathrm{S} \phi-$ rensen et al., 1997; Fong et al., 2007; Valk-Weeber et al., 2020a). It can be hypothesized that the GlyCAM-1 concentration in the serum phase increases at a higher milk fat content as a result of disruption of the MFGM by freezing and thawing of the milk during sample processing (McPherson and Kitchen, 1983). However, the contribution of proteins from the MFGM to the total 


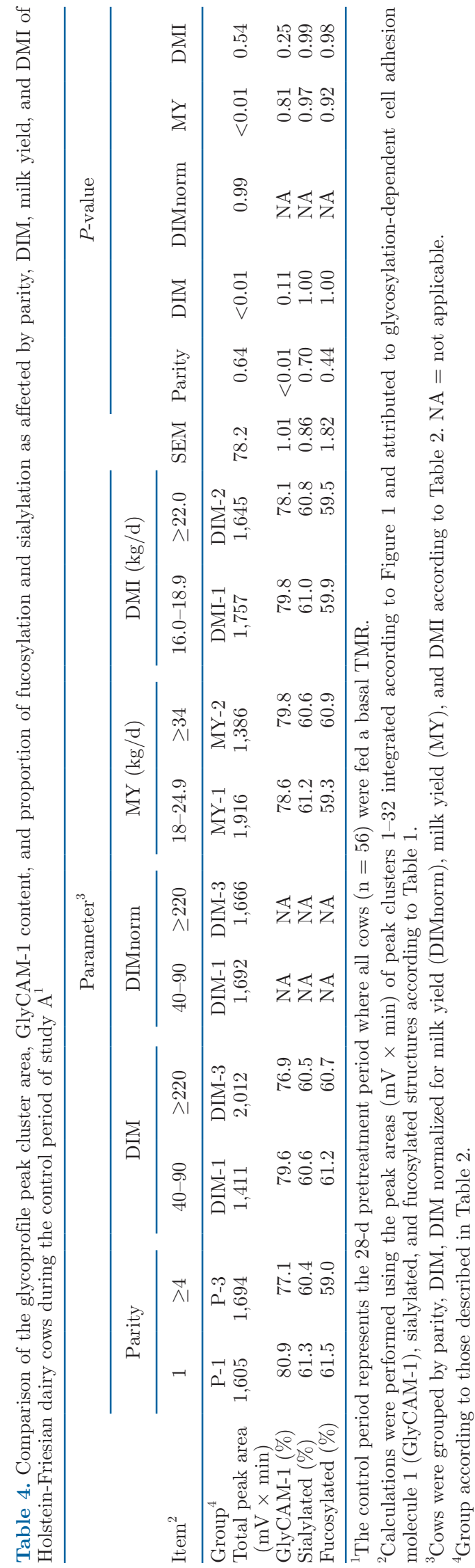

fat globule mass is relatively modest (1.8\%; Dewettinck et al., 2008). The concentration of GlyCAM-1 to the MFGM protein content was determined to be $4.5 \%$ relative to total butyrophilin, the main protein of the MFGM (Lu et al., 2016). The amount of butyrophilin was determined to be $1.15 \mathrm{~g} / 100 \mathrm{~g}$ of total milk protein, whereas in the same study GlyCAM-1 (PP3) was determined to be $1.00 \mathrm{~g} / 100 \mathrm{~g}$ of total protein (Bär et al., 2019). Considered together, the elevated contribution of GlyCAM-1 in milk serum in response to dietary fat supplementation cannot be fully explained by GlyCAM-1 association with the MFGM. Alternatively, fat supplementation may have increased the GlyCAM-1 concentration, or altered the relative concentration of lactoferrin and IgG, which would also produce an apparent increase in GlyCAM-1 contribution.

Milk total protein (whey + casein) content increased in response to protein (Nichols et al., 2018), but the concentration of the glycosylated whey proteins, as indicated by the total chromatogram peak area, did not increase with protein supplementation $(P=0.36$; Table 5). This suggests that the increase in milk protein content observed by Nichols et al. (2018) probably arose from increases in the non- $N$-glycosylated protein portion of the milk, such as caseins and $\beta$-lactoglobulin. These proteins are either exclusively $O$-glycosylated or not glycosylated (Kontopidis et al., 2004; Jensen et al., 2015) and therefore are not quantified in the current analysis of the $N$-linked glycoprofiles.

Study B. We observed clear visual differences in the glycoprofiles of the 6 cows abomasally infused with GG, LG, or EAA in study B (Figure 3). The degree of fucosylation was relatively stable throughout the infusion periods for some cows (cow B3; Figure 3), whereas others displayed notable differences (cows B1, B2, and B5; Figure 3) where specific peaks shifted in intensity in response to the treatment infusions (i.e., nonfucosylated: 4, 13, 15, 24, and 30; fucosylated: 8, 16, 18, 19, 27 , and 31 ; Figure 3 ). However, total $N$-glycan peak area, GlyCAM-1 contribution, and the proportion of sialylated or fucosylated glycans were not significantly affected by the infusion treatments $(P \geq 0.12$; Table 6$)$. Instead, the major determining factor for the degree of sialylation and fucosylation in study B was intercow differences (Table 7). It is possible that the intercow variation in glycan composition introduced variation that impaired detection of the effect of the nutrient infusions on glycoprofiles.

An important observation is that infusions of GG, LG, or EAA in study B resulted in larger fluctuations (up to $\pm 18 \%$; Supplemental Table S2) in fucosylation than protein and fat supplementation in study A $(\leq 4 \%$ variation between control and treatment; Supplemental Table S2; compare Figures 2 and 3). This difference in 

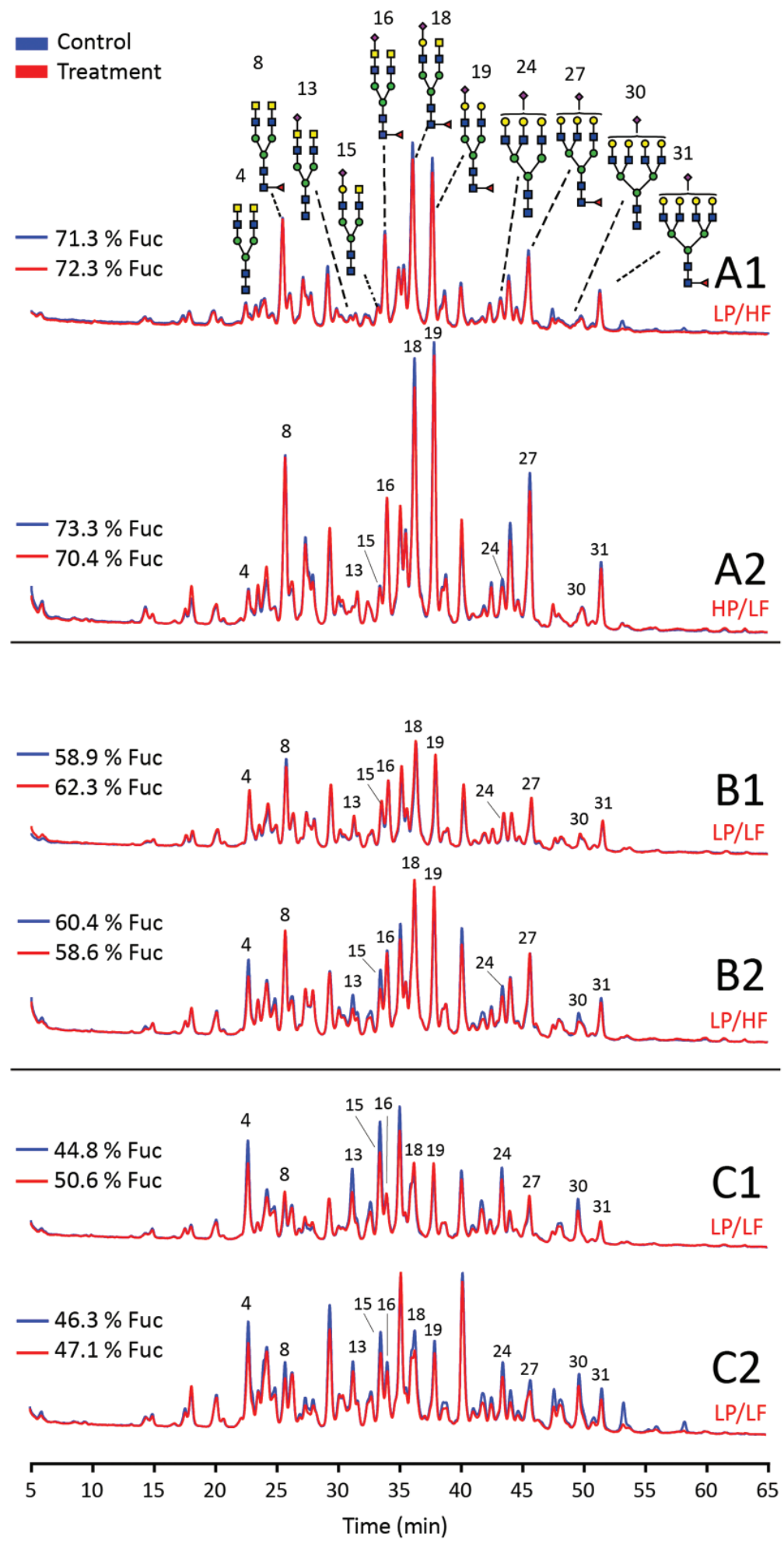

Figure 2. Annotated chromatograms of the overall whey protein glycoprofiles and degree of fucosylation shown for a selection of 6 cows from study A. Peak clusters are annotated according to Figure 1. The blue line illustrates the control period chromatogram, and the red line illustrates the treatment period chromatogram. Cows were grouped by the contribution of fucosylated (\% Fuc) glycans to the overall glycoprofile during the control period (blue line). Group $\mathrm{A}=\sim 70 \%$ Fuc, group $\mathrm{B}=\sim 60 \%$ Fuc, group $\mathrm{C}=\sim 45 \%$ Fuc; 2 cows represented per group. LP/LF $=$ basal TMR fed at $95 \%$ of ad libitum intake with no protein or fat supplement; HP/LF = TMR fed at $95 \%$ of ad libitum intake supplemented daily with $2.0 \mathrm{~kg}$ of SoyPass + RaPass (Borregaard LignoTech, Sarpsborg, Norway) on a DM basis; LP/HF = TMR fed at 95\% of ad libitum intake supplemented daily with $0.68 \mathrm{~kg}$ of Hidropalm (Norel Animal Nutrition, Madrid, Spain) on a DM basis. 
Table 5. Whey glycoprofile composition of Holstein-Friesian dairy cows receiving a basal diet (LP/LF) or diets supplemented with energy from protein $(\mathrm{HP} / \mathrm{LF})$, fat $(\mathrm{LP} / \mathrm{HF})$, or protein and fat $(\mathrm{HP} / \mathrm{HF})$ in study $\mathrm{A}$

\begin{tabular}{|c|c|c|c|c|c|c|c|c|}
\hline Item $^{1}$ & \multicolumn{4}{|c|}{ Treatment $^{2}$} & SEM & \multicolumn{3}{|c|}{$P$-value ${ }^{3}$} \\
\hline GlyCAM-1 (\%) & 77.8 & 78.0 & 78.7 & 79.2 & 0.42 & 0.42 & 0.01 & 0.63 \\
\hline Sialylated (\%) & 60.0 & 59.9 & 60.8 & 60.5 & 0.47 & 0.66 & 0.10 & 0.84 \\
\hline Fucosylated (\%) & 59.8 & 60.9 & 60.4 & 61.3 & 0.70 & 0.14 & 0.48 & 0.85 \\
\hline
\end{tabular}

${ }^{1}$ Calculations were performed using the peak areas $(\mathrm{mV} \times \mathrm{min})$ of peak clusters $1-32$ integrated according to Figure 1 and attributed to glycosylation-dependent cell adhesion molecule 1 (GlyCAM-1), sialylated, and fucosylated structures according to Table 1.

${ }^{2} \mathrm{LP} / \mathrm{LF}=$ basal TMR fed at $95 \%$ of ad libitum intake with no protein or fat supplement; HP/LF $=$ TMR fed at $95 \%$ of ad libitum intake supplemented daily with $2.0 \mathrm{~kg}$ of SoyPass + RaPass (Borregaard LignoTech, Sarpsborg, Norway) on a DM basis; LP/HF $=$ TMR fed at $95 \%$ of ad libitum intake supplemented daily with $0.68 \mathrm{~kg}$ of Hidropalm (Norel Animal Nutrition, Madrid, Spain) on a DM basis; HP $/ \mathrm{HF}=\mathrm{TMR}$ fed at $95 \%$ of ad libitum intake supplemented daily with $2.0 \mathrm{~kg}$ of SoyPass + RaPass and $0.68 \mathrm{~kg}$ of Hidropalm on a DM basis. For all treatments $\mathrm{n}=14$. ${ }^{3} \mathrm{PT}=$ effect of energy from protein; FT $=$ effect of energy from fat.

variation in fucosylation between the 2 studies suggests that the site of delivery and duration of macronutrient supplementation may affect mechanisms underlying the glycosylation process. The glycosylation process requires uridine diphosphate $N$-acetylglucosamine, which results from the hexosamine pathway that ties together AA, GG, and fatty acid metabolism (Hart et al., 2011). The addition of fucose to the glycan structure depends on the availability of the nucleotide sugar substrate (guanosine 5'-diphospho- $\beta$-L-fucose; GDP-Fuc) and
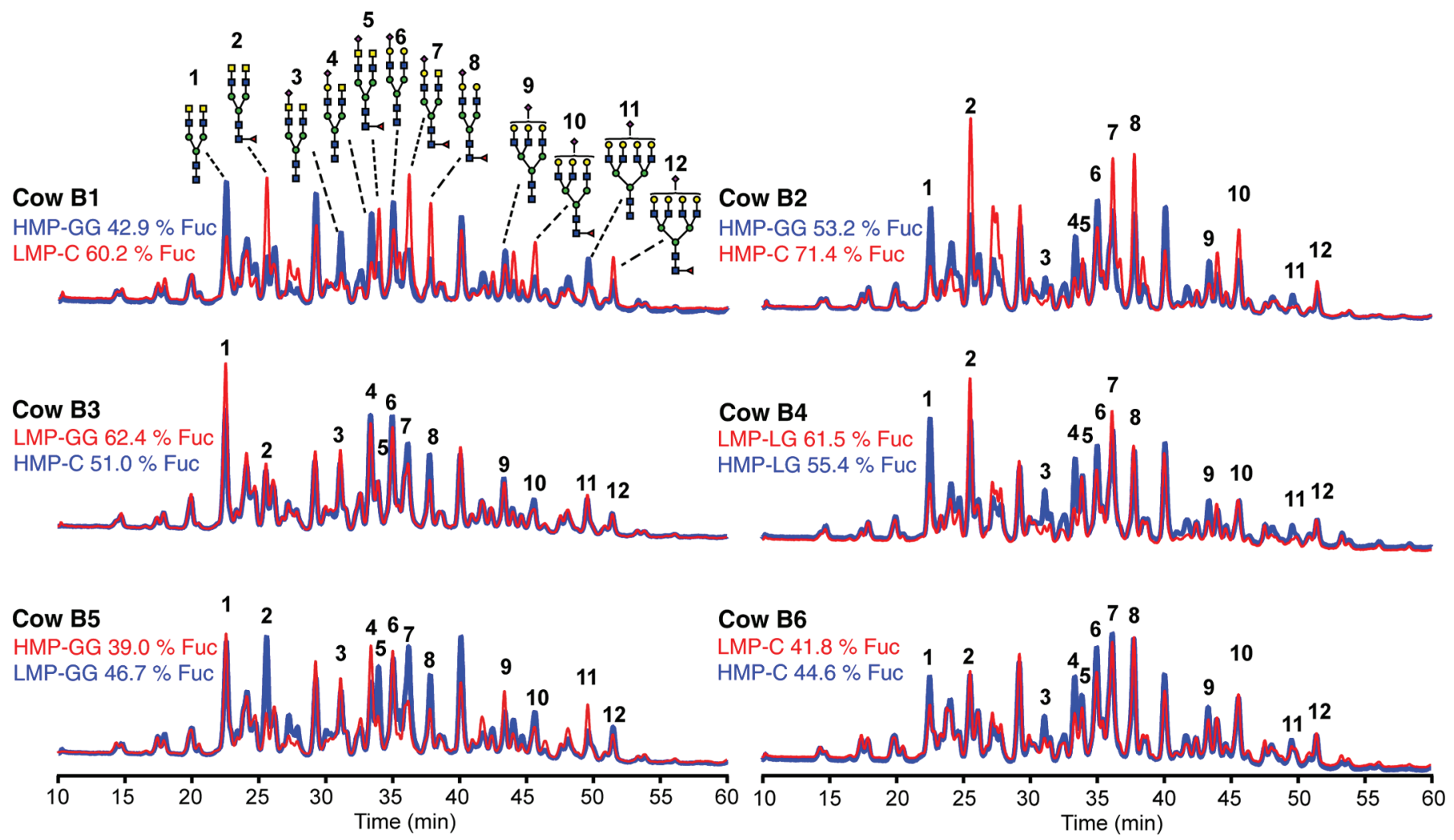

Figure 3. Annotated chromatograms of the overall whey protein glycoprofiles and degree of fucosylation of a selection of the infusion periods of the 6 cows of study B (B1-6). \% Fuc = the percentage of fucosylated glycan structures represented in the chromatogram (degree of fucosylation). Peak clusters were annotated according to Figure 1. Low MP (LMP) or high MP (HMP) abomasal infusion treatments with saline (control; C), glucose (GG), and palm olein (LG): LMP-C =0.9\% saline; LMP-GG = 1,319 g/d of glucose; LMP-LG $=676 \mathrm{~g} / \mathrm{d}$ of palm olein; $\mathrm{HMP}-\mathrm{C}=844 \mathrm{~g} / \mathrm{d}$ of a complete EAA mixture in the same profile and amount as found in $1.5 \mathrm{~kg}$ of casein; HMP-GG $=1,319 \mathrm{~g} / \mathrm{d}$ of glucose + $844 \mathrm{~g} / \mathrm{d}$ of EAA; HMP-LG $=676 \mathrm{~g} / \mathrm{d}$ of palm olein $+844 \mathrm{~g} / \mathrm{d}$ of EAA. An overview of the glycoprofile chromatograms of all infusion periods for the 6 cows and the degree of fucosylation is provided by Supplemental Figures S1 and S2 (http://dx.doi.org/10.17632/88h99xfmp8.1) 
the activity of fucosyltransferase 8 (FUT8). Both GDP-Fuc availability and FUT8 activity are affected by macronutrient supply in rats (Cortes et al., 1988; Biol et al., 1992). In the current analysis, mechanisms underlying glycan fucosylation may have been more sensitive to the relatively higher dose of postruminal EAA infused in study B $(844 \mathrm{~g} / \mathrm{d})$ compared with the mixture of rumen-protected soybean meal and rapeseed meal fed in study A (delivered $449 \mathrm{~g} / \mathrm{d}$ of digestible EAA). Further, the fat supplement in study A provided a mix of predominantly saturated $\mathrm{C} 16$ and $\mathrm{C} 18$ fatty acids, whereas the monounsaturated LG infused in study B provided a mix of predominantly $\mathrm{C} 16$ and C18:1. These differences in nutrient supply could have affected the delicate balance in cellular availability of metabolites, resulting in the observed differences between the studies. The fucosylation process, GDP-Fuc availability, and FUT8 activity in response to metabolite supply to the bovine mammary gland clearly warrant further study.

Differences in the length of the experimental periods between study A and B and the subsequent time for mammary gland adaptation to nutritional interventions also may have been factors contributing to the different magnitude of glycoprofile variation observed between the studies. Variation in fucosylation of the structures of GlyCAM-1 could be a short-term effect. In the case of study A (longitudinal design), any short-term response altering fucosylation may have been resolved and the glycoprofile restored to baseline at the time of sampling (after $21 \mathrm{~d}$ of exposure to the treatment diets). In study B (Latin square design), the samples were taken during the final $3 \mathrm{~d}$ of the 5 -d infusion, which may have been too early for full stabilization of the glycoprofile. At present it cannot be excluded that the glycoprofiles observed in study B represent a phase of adaptation to changes in macronutrient supply.

\section{Control and Function of GlyCAM-1 Fucosylation}

Outside of the colostrum period, the glycan fingerprint of bovine lactoferrin is very stable between individual cows of mixed breed and throughout lactation (>30 DIM; Valk-Weeber et al., 2020b). Results of the current study show that the glycosylation of GlyCAM-1 is regulated less strictly than that of lactoferrin, and we report clear variation in the GlyCAM-1 glycoprofile outside of the brief colostrum phase. Assuming that influential environmental factors were adequately controlled for in the animal experiments (i.e., identical housing conditions for each cow and measurements taken at the same time of year within study, randomizing cows across treatments based on parity, lactation stage, and feed intake), differences in

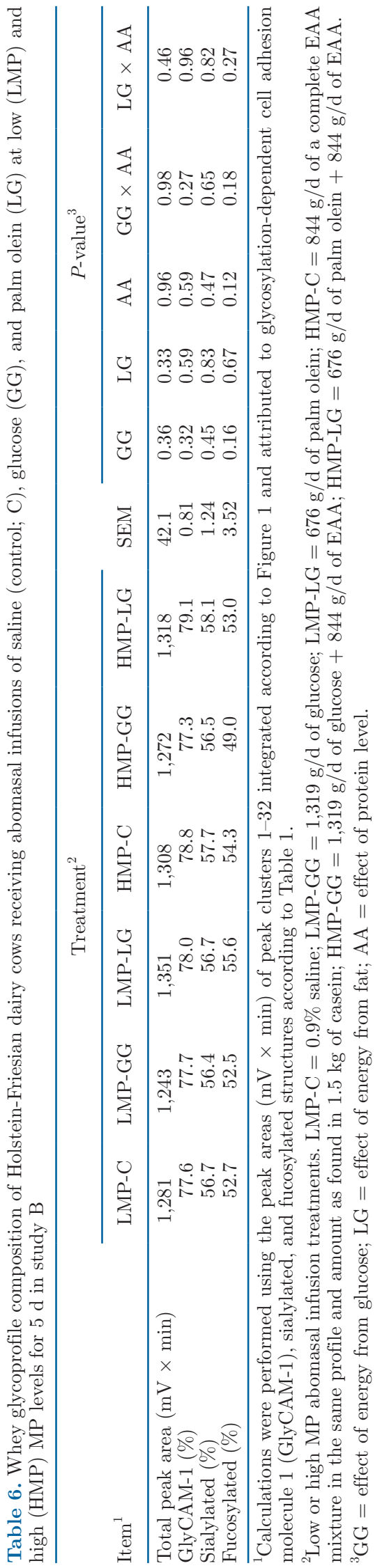


Table 7. Comparison of whey glycoprofile peak cluster areas and composition between lactating Holstein-Friesian dairy cows in study B

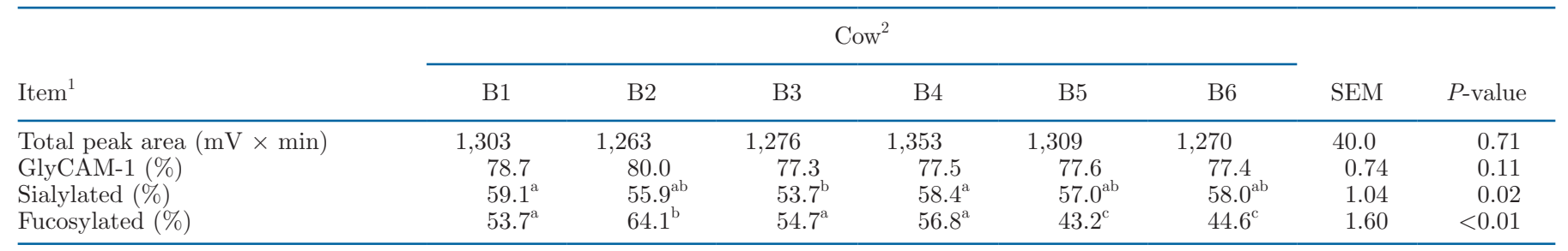

${ }^{\mathrm{a}-\mathrm{c}}$ Means within a row with different superscripts differ $(P<0.05)$.

${ }^{1}$ Calculations were performed using the peak areas $(\mathrm{mV} \times \min )$ of peak clusters $1-32$ integrated according to Figure 1 and attributed to glycosylation-dependent cell adhesion molecule 1 (GlyCAM-1), sialylated, and fucosylated structures according to Table 1.

${ }^{2}$ Individual cows (B1-B6) receiving abomasal infusions for $5 \mathrm{~d}$. Data are LSM and SEM calculated for individual cows over each period.

glycoprofile between individual Holstein-Friesian cows (Figure 2 and 3) may be explained by a strong genetic component that affects the glycosylation pattern on an individual-cow basis. In contrast to other milk proteins, gene expression of GlyCAM-1 is not triggered by insulin, prolactin, and glucocorticoids (Nishimura and Kohmoto, 2001), suggesting a different regulation of this protein; however, currently no information is available about factors influencing its glycosylation in lactating mammary glands. Based on protein concentration and glycan contribution, GlyCAM-1 is the major $N$-glycosylated protein (Table 3) in both bovine milk serum and whey protein-based products (Valk-Weeber et al., 2020a). Unique functions for GlyCAM-1 and its glycans remain to be identified, although evidence exists for antimicrobial and mucin-like lubricating properties of this protein (Dowbenko et al., 1993; Campagna et al., 2004). The glycans of GlyCAM-1 likely provide a specific functionality. The observed variable nature of GlyCAM-1 fucosylation described here may represent an adaptive process in response to altered nutrient supply and metabolic conditions within mammary cells. Core fucosylation of glycans stabilizes the glycan structure and highly affects the capacity of glycans to interact with receptors (Falconer et al., 2018). Compared with the normal (control) glycan structures of lactoferrin, modified glycans had a significantly different effect on Toll-like receptor signaling (Figueroa-Lozano et al., 2018). Hypothetically, the observed variation in the degree of fucosylation of GlyCAM-1 may also affect its receptor-interaction capacity or its possible role in immune system activation and regulation.

In both study A and study B, cows were not selected or grouped based on their protein fucosylation level (i.e., glycoprofiles of the cows at the start of each treatment period were randomly distributed per group). The effect of the initial degree of fucosylation on the outcome of nutrient-induced alterations remains to be explored. Grouping by the initial degree of fucosylation and use of a lengthened adaptation period for the nutritional treatments may serve to identify the main determinants that induce variation. Supplementation with nutrients other than fatty acids, GG, or EAA may also induce changes in fucosylation of GlyCAM-1. Mono- and polysaccharides have been reported to alter the sialylation of serum glycoproteins in humans (Alavi et al., 2011) and are interesting targets to investigate for effects on bovine GlyCAM-1 glycosylation. Here we focused on the $N$-linked glycans of GlyCAM-1, but this protein is also modified by phosphorylation and $O$-glycosylation (Girardet and Linden, 1996; Coddeville et al., 1998). Effects of nutrient infusions on these types of modifications and potential protein functionality remain to be explored.

\section{CONCLUSIONS}

Here, we report considerable variations in the glycoprofiles of whey proteins of Holstein-Friesian cows. The main intercow differences were observed in the degree of fucosylation of the $\mathrm{N}$-glycans of GlyCAM-1. Although the other main glycoproteins in bovine whey, lactoferrin and $\operatorname{IgG}$, also have a relatively stable glycosylation pattern between individual cows, GlyCAM-1 shows potential for strong variation. Dietary supplementation with protein and fat did not significantly alter the whey $N$-glycosylation patterns. Abomasal infusions with LG, GG, or EAA resulted in intracow shifts in the GlyCAM-1-specific fucosylated and nonfucosylated glycan structures; these shifts could not be statistically attributed to the infused nutrients. Intra- and intercow variations for GlyCAM-1 glycosylation have not been reported previously, nor has it been shown that GlyCAM-1 glycosylation can be modified outside of the colostrum phase. Thus, GlyCAM-1 differs from other major whey glycoproteins, such as lactoferrin, that display tight regulation of glycosylation throughout lactation, with the exception of the short colostrum phase. Fucosylation is an important epitope for receptor interaction, and further research is needed to unravel the function of GlyCAM-1 as well as the effects of different glycoprofiles on its functionality. 


\section{ACKNOWLEDGMENTS}

The work of Rivca Valk-Weeber, Sander S. van Leeuwen, and Lubbert Dijkhuizen was financially supported by FrieslandCampina (Amersfoort, the Netherlands), the University of Groningen/Campus Fryslân (Groningen, the Netherlands), and the University of Groningen (Groningen, the Netherlands). Milk samples were obtained from research conducted by Wageningen University and Research (Wageningen Livestock Research, Wageningen, the Netherlands), commissioned and funded by the Ministry of Agriculture, Nature and Food Quality (The Hague, the Netherlands) within the framework of Policy Support Research theme "Feed4Foodure" (BO-31.03-005-001; TKI-AF12039B), and by the Vereniging Diervoederonderzoek Nederland (Rijswijk, the Netherlands). The authors have not stated any conflicts of interest.

\section{REFERENCES}

Alavi, A., O. Fraser, E. Tarelli, M. Bland, and J. Axford. 2011. An open-label dosing study to evaluate the safety and effects of a dietary plant-derived polysaccharide supplement on the $N$-glycosylation status of serum glycoproteins in healthy subjects. Eur. J. Clin. Nutr. 65:648-656. https://doi.org/10.1038/ejcn.2010.263.

Bär, C., D. Mathis, P. Neuhaus, D. Dürr, W. Bisig, L. Egger, and R. Portmann. 2019. Protein profile of dairy products: Simultaneous quantification of twenty bovine milk proteins. Int. Dairy J. 97:167-175. https://doi.org/10.1016/j.idairyj.2019.01.001.

Barboza, M., J. Pinzon, S. Wickramasinghe, J. W. Froehlich, I. Moeller, J. T. Smilowitz, L. R. Ruhaak, J. Huang, B. Lonnerdal, J. B. German, J. F. Medrano, B. C. Weimer, and C. B. Lebrilla. 2012. Glycosylation of human milk lactoferrin exhibits dynamic changes during early lactation enhancing its role in pathogenic bacteria-host interactions. Mol. Cell. Proteomics 11:M111.015248. https://doi.org/10.1074/mcp.M111.015248.

Bigge, J. C., T. P. Patel, J. A. Bruce, P. N. Goulding, S. M. Charles, and R. B. Parekh. 1995. Nonselective and efficient fluorescent labeling of glycans using 2-amino benzamide and anthranilic acid. Anal. Biochem. 230:229-238. https://doi.org/10.1006/abio.1995 .1468 .

Biol, M. C., A. Martin, and P. Louisot. 1992. Nutritional and developmental regulation of glycosylation processes in digestive organs. Biochimie 74:13-24. https://doi.org/10.1016/0300-9084(92)90180 $-\mathrm{M}$.

Campagna, S., A. G. Mathot, Y. Fleury, J. M. Girardet, and J. L. Gaillard. 2004. Antibacterial activity of lactophoricin, a synthetic 23-residues peptide derived from the sequence of bovine milk component-3 of proteose peptone. J. Dairy Sci. 87:1621-1626.

Cheng, J. B., J. Q. Wang, D. P. Bu, G. L. Liu, C. G. Zhang, H. Y. Wei, L. Y. Zhou, and J. Z. Wang. 2008. Factors affecting the lactoferrin concentration in bovine milk. J. Dairy Sci. 91:970-976. https://doi .org/10.3168/jds.2007-0689.

Coddeville, B., J. M. Girardet, Y. Plancke, S. Campagna, G. Linden, and G. Spik. 1998. Structure of the $O$-glycopeptides isolated from bovine milk component PP3. Glycoconj. J. 15:371-378. https:// doi.org/10.1023/A:1006973802139.

Conesa, C., M. Lavilla, L. Sánchez, M. D. Pérez, L. Mata, P. Razquín, and M. Calvo. 2005. Determination of IgG levels in bovine bulk milk samples from different regions of Spain. Eur. Food Res. Technol. 220:222-225. https://doi.org/10.1007/s00217-004-1016-0.

Cortes, P., F. Dumler, D. L. Paielli, and N. W. Levin. 1988. Glomerular uracil nucleotide synthesis: Effects of diabetes and protein intake. Am. J. Physiol. 255:F647-F655. https://doi.org/10.1152/ ajprenal.1988.255.4.F647.

de Kivit, S., A. D. Kraneveld, J. Garssen, and L. E. M. Willemsen. 2011. Glycan recognition at the interface of the intestinal immune system: Target for immune modulation via dietary components. Eur. J. Pharmacol. 668:S124-S132. https://doi.org/10.1016/j .ejphar.2011.05.086.

Dewettinck, K., R. Rombaut, N. Thienpont, T. T. Le, K. Messens, and J. Van Camp. 2008. Nutritional and technological aspects of milk fat globule membrane material. Int. Dairy J. 18:436-457. https:// doi.org/10.1016/j.idairyj.2007.10.014.

Dowbenko, D., A. Kikuta, C. Fennie, N. Gillett, and L. A. Lasky. 1993. Glycosylation-dependent cell adhesion molecule 1 (GlyCAM 1) mucin is expressed by lactating mammary gland epithelial cells and is present in milk. J. Clin. Invest. 92:952-960.

Eisenberg, S. W. F., E. Veldman, V. P. M. G. Rutten, and A. P. Koets. 2015. A longitudinal study of factors influencing the result of a Mycobacterium avium ssp. paratuberculosis antibody ELISA in milk of dairy cows. J. Dairy Sci. 98:2345-2355. https://doi.org/10 3168/jds.2014-8380.

European Commission. 2010. Directive 2010/63/EU of the European Parliament and of the council of 22 September 2010 on the protection of animals used for scientific purposes. Accessed Oct. 12 2018. https://eur-lex.europa.eu/eli/dir/2010/63/oj.

Falconer, D. J., G. P. Subedi, A. M. Marcella, and A. W. Barb. 2018. Antibody fucosylation lowers the Fc $\gamma$ RIIIa/CD16a affinity by limiting the conformations sampled by the N162-glycan. ACS Chem. Biol. 13:2179-2189. https://doi.org/10.1021/acschembio.8b00342.

Figueroa-Lozano, S., R. L. Valk-Weeber, R. Akkerman, W. Abdulahad, S. S. van Leeuwen, L. Dijkhuizen, and P. de Vos. 2020. Inhibitory effects of dietary $\mathrm{N}$-glycans from bovine lactoferrin on Toll-like receptor 8; Comparing efficacy with chloroquine. Front. Immunol. 11:790. https://doi.org/10.3389/fimmu.2020.00790.

Figueroa-Lozano, S., R. L. Valk-Weeber, S. S. van Leeuwen, L. Dijkhuizen, and P. de Vos. 2018. Dietary $N$-glycans from bovine lactoferrin and TLR modulation. Mol. Nutr. Food Res. 62:1700389. https://doi.org/10.1002/mnfr.201700389.

Fong, B. Y., C. S. Norris, and A. K. H. MacGibbon. 2007. Protein and lipid composition of bovine milk-fat-globule membrane. Int. Dairy J. 17:275-288. https://doi.org/10.1016/j.idairyj.2006.05.004.

Gellrich, K., H. H. D. Meyer, and S. Wiedemann. 2014. Composition of major proteins in cow milk differing in mean protein concentration during the first 155 days of lactation and the influence of season as well as short-term restricted feeding in early and mid-lactation. Czech J. Anim. Sci. 59:97-106. https://doi.org/10 $.17221 / 7289-$ CJAS

Girardet, J. M., and G. Linden. 1996. PP3 component of bovine milk: A phosphorylated whey glycoprotein. J. Dairy Res. 63:333-350. https://doi.org/10.1017/S0022029900031848.

Hart, G. W., C. Slawson, G. Ramirez-Correa, and O. Lagerlof. 2011. Cross talk between $O$-GlcNAcylation and phosphorylation: Roles in signaling, transcription, and chronic disease. Annu. Rev. Biochem. 80:825-858. https://doi.org/10.1146/annurev-biochem $-060608-102511$.

Henriquez, D. S., H. M. Tepperman, and J. Tepperman. 1979. Effects of high-glucose and high-fat diets on concanavalin A binding to rat liver plasma membranes and on the amount and pattern of their glycoprotein carbohydrates. J. Lipid Res. 20:624-630.

Jensen, H. B., K. S. Pedersen, L. B. Johansen, N. A. Poulsen, M. Bakman, D. E. W. Chatterton, and L. B. Larsen. 2015. Genetic variation and posttranslational modification of bovine $\kappa$-casein: Effects on caseino-macropeptide release during renneting. J. Dairy Sci. 98:747-758. https://doi.org/10.3168/jds.2014-8678.

Kontopidis, G., C. Holt, and L. Sawyer. 2004. Invited review: 3-Lactoglobulin: Binding properties, structure, and function. J. Dairy Sci. 87:785-796. https://doi.org/10.3168/jds.S0022 -0302(04)73222-1.

Lu, J., N. Argov-Argaman, J. Anggrek, S. Boeren, T. van Hooijdonk, J. Vervoort, and K. A. Hettinga. 2016. The protein and lipid composition of the membrane of milk fat globules depends on their 
size. J. Dairy Sci. 99:4726-4738. https://doi.org/10.3168/jds.2015 -10375 .

McPherson, A. V., and B. J. Kitchen. 1983. Reviews of the progress of Dairy Science: The bovine milk fat globule membrane-Its formation, composition, structure and behaviour in milk and dairy products. J. Dairy Res. 50:107-133. https://doi.org/10.1017/ S0022029900032581.

Neelamegham, S., and L. K. Mahal. 2016. Multi-level regulation of cellular glycosylation: From genes to transcript to enzyme to structure. Curr. Opin. Struct. Biol. 40:145-152. https://doi.org/ 10.1016/j.sbi.2016.09.013.

Nichols, K., A. Bannink, S. Pacheco, H. J. van Valenberg, J. Dijkstra, and H. van Laar. 2018. Feed and nitrogen efficiency are affected differently but milk lactose production is stimulated equally when isoenergetic protein and fat is supplemented in lactating dairy cow diets. J. Dairy Sci. 101:7857-7870. https://doi.org/10.3168/jds .2017-14276.

Nichols, K., J. Dijkstra, H. van Laar, S. Pacheco, H. J. van Valenberg, and A. Bannink. 2019. Energy and nitrogen partitioning in dairy cows at low or high metabolizable protein levels is affected differently by postrumen glucogenic and lipogenic substrates. J. Dairy Sci. 102:395-412. https://doi.org/10.3168/jds.2018-15249.

Nishimura, T., and K. Kohmoto. 2001. Regulation of glycosylation-dependent cell adhesion molecule 1 (GlyCAM-1) gene in the mouse mammary gland differs from that of casein genes. Comp. Biochem. Physiol. B Biochem. Mol. Biol. 129:149-156.

NRC. 2001. Nutrient Requirements of Dairy Cattle. 7th rev. ed. Natl. Acad. Sci., Washington, DC.

Ohtsubo, K., and J. D. Marth. 2006. Glycosylation in cellular mechanisms of health and disease. Cell 126:855-867. https://doi.org/10 $.1016 /$ j.cell.2006.08.019.

Raimondo, R. F. S., J. S. P. Ferraõ, S. I. Miyashiro, P. T. Ferreira, J. P. E. Saut, D. B. Birgel, and E. H. Birgel Junior. 2019. The dynamics of individual whey protein concentrations in cows' mammary secretions during the colostral and early lactation periods. J. Dairy Res. 86:88-93. https://doi.org/10.1017/S0022029918000808.

Rodrigues, E., and M. S. Macauley. 2018. Hypersialylation in cancer: Modulation of inflammation and therapeutic opportunities. Cancers (Basel) 10:207. https://doi.org/10.3390/cancers10060207.

Ruhaak, L. R., C. Huhn, W. J. Waterreus, A. R. De Boer, C. Neusüss, C. H. Hokke, A. M. Deelder, and M. Wuhrer. 2008. Hydrophilic interaction chromatography-based high-throughput sample preparation method for $\mathrm{N}$-glycan analysis from total human plasma glycoproteins. Anal. Chem. 80:6119-6126. https://doi.org/10.1021/ ac800630x.
Sørensen, E. S., L. K. Rasmussen, L. Møller, and T. E. Petersen. 1997. The localization and multimeric nature of component PP3 in bovine milk: Purification and characterization of PP3 from caprine and ovine milks. J. Dairy Sci. 80:3176-3181. https://doi.org/10 .3168/jds.S0022-0302(97)76289-1.

Takimori, S., H. Shimaoka, J. I. Furukawa, T. Yamashita, M. Amano, N. Fujitani, Y. Takegawa, L. Hammarström, I. Kacskovics, Y. Shinohara, and S. I. Nishimura. 2011. Alteration of the N-glycome of bovine milk glycoproteins during early lactation. FEBS J. 278:3769-3781. https://doi.org/10.1111/j.1742-4658.2011.08299.x.

Valk-Weeber, R. L., C. Deelman-Driessen, L. Dijkhuizen, T. Eshuisde Ruiter, and S. S. van Leeuwen. 2020a. In depth analysis of the contribution of specific glycoproteins to the overall bovine whey $N$-Linked glycoprofile. J. Agric. Food Chem. 68:6544-6553. https: //doi.org/10.1021/acs.jafc.0c00959.

Valk-Weeber, R. L., T. Eshuis-de Ruiter, L. Dijkhuizen, and S. S. van Leeuwen. 2020b. Dynamic temporal variations in bovine lactoferrin glycan structures. J. Agric. Food Chem. 68:549-560. https:// doi.org/10.1021/acs.jafc.9b06762.

Valk-Weeber, R. L., T. Eshuis-de Ruiter, L. Dijkhuizen, and S. S. van Leeuwen. 2020c. Quantitative analysis of bovine whey glycoproteins using the overall $N$-linked whey glycoprofile. Int. Dairy J. 110:104814. https://doi.org/10.1016/j.idairyj.2020.104814.

Varki, A., and P. Gagneux. 2012. Multifarious roles of sialic acids in immunity. Ann. N. Y. Acad. Sci. 1253:16-36. https://doi.org/10 .1111/j.1749-6632.2012.06517.x.

Wang, W.-L., W. Wang, Y.-M. Du, H. Wu, X.-B. Yu, K.-P. Ye, C.-B. Li, Y.-S. Jung, Y.-J. Qian, J. Voglmeir, and L. Liu. 2017. Comparison of anti-pathogenic activities of the human and bovine milk $N$-glycome: Fucosylation is a key factor. Food Chem. 235:167-174. https://doi.org/10.1016/j.foodchem.2017.05.026.

Williams, E. J. 1949. Experimental designs balanced for the estimation of residual effects of treatments. Aust. J. Chem. 2:149-168. https: //doi.org/10.1071/CH9490149.

\section{ORCIDS}

Rivca L. Valk-Weeber ํㅡ https://orcid.org/0000-0001-7186-6045

Kelly Nichols () https://orcid.org/0000-0001-6062-7460

Lubbert Dijkhuizen @ \ttps://orcid.org/0000-0003-2312-7162

Etske Bijl @ https://orcid.org/0000-0002-7363-5387

Sander S. van Leeuwen (ํ) https://orcid.org/0000-0003-0017-2841 